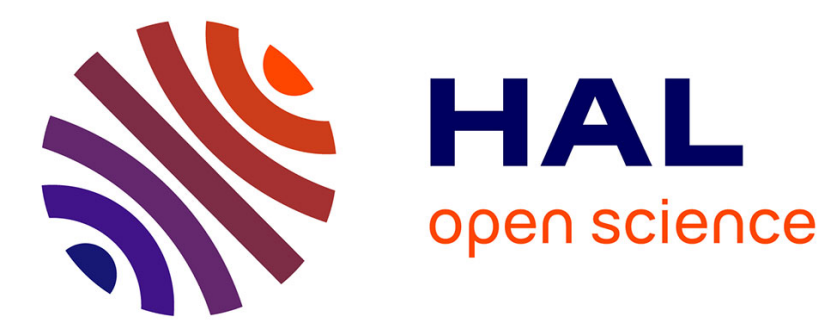

\title{
Using the World Wide Web to Build Learning Communities in $\mathrm{K}-12$
}

\author{
Douglas N. Gordin, Louis M. Gomez, Roy D. Pea, Barry J. Fishman
}

\section{To cite this version:}

Douglas N. Gordin, Louis M. Gomez, Roy D. Pea, Barry J. Fishman. Using the World Wide Web to Build Learning Communities in K- 12. Journal of Computer-Mediated Communications, 1996, 2(3), 33 p. hal-00190601

\section{HAL Id: hal-00190601 https://telearn.archives-ouvertes.fr/hal-00190601}

Submitted on 23 Nov 2007

HAL is a multi-disciplinary open access archive for the deposit and dissemination of scientific research documents, whether they are published or not. The documents may come from teaching and research institutions in France or abroad, or from public or private research centers.
L'archive ouverte pluridisciplinaire HAL, est destinée au dépôt et à la diffusion de documents scientifiques de niveau recherche, publiés ou non, émanant des établissements d'enseignement et de recherche français ou étrangers, des laboratoires publics ou privés. 
Using the World Wide Web

to Build

Learning Communities in $\mathrm{K}-12$

Douglas N. Gordin, Louis M. Gomez, Roy D. Pea, Barry J. Fishman

Northwestern University

School of Education and Social Policy

2115 N. Campus Drive

Evanston IL. 60208

(gordin@covis.nwu.edu,gomez@covis.nwu.edu,pea@covis.nwu.edu,

bfishman@covis.nwu.edu)

Many are the conditions which must be fulfilled if the Great

Society is to become a Great Community .... The highest and most

difficult kind of inquiry and a subtle, delicate, vivid and

responsive art of communication must take possession of the

physical machinery of transmission and circulation and breath

life into it. When the machine age has thus perfected its

machinery, it will be a means of life and not its despotic

master. John Dewey (1938)

Table of Contents

\section{Abstract}

1. Introduction

2. Role of Communications in Learning Communities

3. The World Wide Web

4. Access to Resources

5. Access to Analysis Tools and Raw Data

6. Forging Learning Communities through Communication Mediums on the WWW

7. Collaboration between Students and Work-Based Learning Communities

8. Adopting students work into a community of practice

9. The Need for WWW Educational Server Development Guidelines

10. The Geosciences Server: a sample Educational WWW Server

11. Conclusion 
Bibliography

Footnotes

\begin{abstract}
Social accounts of learning and human knowledge have led to attempts to reorganize schools as learning communities. This paper examines the utility of World Wide Web (WWW) for aiding in the construction of school-based and work-based learning communities. An ordered list of interactions is provided to characterize the depth of students entry into new learning communities. Current offerings on the WWW are then surveyed in terms of these categories. Finally, proposals are advanced for enhancing the architecture of the WWW to facilitate its use for the creation and operation of learning communities.
\end{abstract}

\title{
1. Introduction
}

Social accounts of learning and human knowledge (Dewey, 1938; Kuhn, 1962; Toulmin,1972; Vygotsky, 1978; Wittgenstein, 1967) have led to attempts to reorganize schools so as to form learning communities(1). In general, two different senses of learning communities have been advanced. First, are school-based learning communities formed by students and teachers who engage in long-term projects; where students work together collaboratively, thus allowing them to learn from one another; and use the problems to be solved to dictate the knowledge that must be acquired, thus frequently and purposefully crossing disciplinary boundaries (Hill, 1982). Second, are work-based learning communities where students learn the practices of a discipline or profession, with the historical example being apprenticeship. Here the profession defines a "community of practice" that the student aspires to join; this term refers broadly to the practices of a field, its social organization, and its mores. This method of learning through apprenticeship has been characterized as becoming a legitimate peripheral participant (Lave \& Wenger, 1991). Schools can play a role here too by helping connect students and work-based learning communities and encouraging students to critically reflect on the communities in which they participate. In fact, these are functions many professional schools 
commonly perform. Essential to all types of learning communities is access to resources and communication. In this light, it is argued herein that computational communication technologies (CCT)2, and, in particular, the World Wide Web, can play a vital role in the formation and successful operation of learning communities.

\section{Role of Communications in Learning Communities}

Learning communities are difficult to build because they have high social and material requirements. School-based learning communities that are attempting to engage in long-term inquiry require access to specialized information, to practitioners, to relevant data and analysis tools, and the means to create arguments and representations so as to negotiate disagreements through them. For example, Dewey proposed that students investigate how the history of cotton production and the impact of those changes on the experience of the workers. Such a survey requires students to trace through the history of technological innovations, interview current workers and investigate the lives of former workers, and to express and discuss their results. A CCT could expedite these needs enormously by, for example, providing ready access to historical documents, books and reference material; provide the means and medium to communicate with appropriate workers; and through helping students to structure their discussion via specialized hypertextual mediums that reify argumentative structure (O'Neill, Gomez, \& Edelson, 1994). The needs of students in work-based learning communities are similarly demanding, including the need to learn about community practices and products, find participants in the community who are looking for an apprenticeship, build and store an accessible portfolio of work, and reflect and critique the apprentice experience. Clearly, a CCT could be useful here as well. It could be argued that apprenticeships have successfully been conducted for thousands of years without the need for CCTs, yet this would miss the point that these new connections to work-based learning communities are not necessarily designed to turn the students into life-long professional practitioners but rather to provide an opportunity for them to understand and investigate a field -- or more to the point, to investigate many fields. The success of apprenticeships historically has demanded years of service where the 
initiate was immersed in all aspects of a profession. The hope is that shorter more focused and more varied experiences can serve to educate students on a variety of fields, thus providing them with the ability to integrate diverse expertise and to choose a field based on experience rather than inheritance or chance. In learning communities students must connect to communities of practice (e.g., when a school-based learning community picks as a class project to build a sturdier or more agile kite it should profitably engage the knowledge of aerodynamics, kite manufacturing, and the atmospheric science). Hence, it is useful to characterize the types of interactions students may have with communities of practice. The following list is designed to describe increasing levels of interaction with a community of practice or fuller levels of participation:

1. Students access published work, such as, papers, figures, presentations, and analyzed data.

2. Students access tools and raw data, such as, equipment for production, laboratory procedures and materials, community developed data sets, and analysis tools.

3. Students dialogue with community members, either written or oral, such as, exchange of letters, email, telephone calls, and interviews.

4. Performance of joint coordinated activities between students and work-based learning communities, such as, performing an experiment together or planning collaborative activities.

5. Incorporating student work into published archives of a community's work (e.g., when scientist collect and use student collected data).

This list will be used to organize the discussion found below of how the World Wide Web (WWW) can be used to form learning communities. The intended value of these categories of use is that they be used to guide next generation WWW application design and future technology adoption strategies. Hence, it is necessary to briefly describe the WWW and the rapid process by which it has become a dominant technology.

\section{The World Wide Web}


In the early and mid 1980's the Internet and inter-networking were dominated by the technical and research community. It was a special-purpose information preserve for the support of communication and inquiry. Starting in the late 80 's and continuing into the early 90 's the Internet experienced explosive growth. For example, in 1987 the number of Internet hosts exceeded 10,000, in 1989 the number of hosts exceeded 100,000, and in 1992 there were over a 1,000,000 Internet hosts (Zakon, 1994). Much of this growth did not come from more technologists and researchers joining the network but from non-traditional entrants to the network community. In particular, students and teachers were introduced to email, news groups, listservs, ftp, and gopher, thus causing a significant part of the network's growth. In a similar fashion the WWW, the most important recent innovation in Internet Protocol technology, have gained a significant foothold in the technical community and are now expanding rapidly into the world beyond the research community, including the K-12 community of students and teachers.

Paralleling the exponential growth of the Internet overall has been the growth of the WWW: Only 18 months ago, there were but 100 WWW servers on-line worldwide, today there are over $10,000 \mathrm{WWW}$ servers and current estimates predict 100,000 a year from now (Gray, 1994). This decentralized development of information resources, for everything from scientific databases to corporate products to traffic and weather reports, is an exciting development for lifelong learning and for education and training.

In the discussion that follows we survey several current applications of WWW technology in K-12 learning situations. The survey follows the categories proposed above detailing students increasing participation in communities of practice. Our survey is not meant to be exhaustive. Indeed by the very decentralized nature of the network an exhaustive report may be impossible. We do however attempt to describe several example K-12 uses of the WWW that are illustrative of the breadth of use and which might be indicative of where school people and others in learning communities may be taking the WWW.

Following our brief use-survey we will speculate on how current WWW 
technology and its potential evolution support the needs of learning communities. Finally, we use both our characterization of WWW use and speculation of its evolution to argue that there are specific needs and identifying characteristics for WWW servers developed for educational purposes. Of course it is likely that any information resource on the network can be learned from, just as any book from the library can offer learning opportunities, whether it is specifically planned for educational uses or not. The potential value of all information resources for learning notwithstanding, it seems to us that a broad set of guidelines for educationally focused WWW servers will spur both new application design and widespread technology adoption in schools and other learning communities.

\section{Access to Resources}

The search for reference and archival information for reports, projects, and other activities is a large part of school work. Thus, students commonly go in search of information in their school and public libraries. Often, a short passage in an encyclopedia meets the student's need, where their goal is to merely summarize commonly accepted information and standard interpretations. However, when students engage in school-based learning communities they must do more than be passive collectors of previously digested information. In pursuit of long-term project and in defense or controversial hypotheses students must find relevant information. The emphasis in on the student using the information, not merely reporting it; developing, stating and defending a position, not merely repeating a status quo. It is in these information seeking situations that we believe the WWW will be most valuable to the K-12 community. Its value stems from the way in which organizations act as publishers for themselves, allowing them to quickly place their new work on-line and to clearly express their own point of view. These distinctive points of view are in one sense biases and therefore inimical to the student knowing the "truth." Yet, this is precisely the antidote to overly sanitized textbooks that is needed. Before students can decide what they believe they must become aware of the range of existing opinions and to identify at least some of them as ones they do not believe. Hence, as students combine information from more traditional sources with WWW 
sources, they originate their own point of view, including critiques of alternatives.

Due to the individualized medium of publishing on the WWW, its diversity nearly defies exposition. Examples are used to illustrate this enormous array of information. However, these example can barely scratch the surface of what is available. Our aim is to show utility to students, rather than to provide even a representative summary.

The information resources for K-12 education provided by the WWW can be divided into the following five categories:

\section{Libraries}

2. Museums

3. Government Information

4. Curriculum and Activities

5. Indices

These categories are a mix of information sources and information format types. However, this mixture accurately reflects the dominant ways that material is currently organized within the WWW. Entries are jointly organized by institution (e.g. universities or libraries) and form (e.g. plain-text article or hyper-text index).

\section{Libraries}

The potential for communication networks to amplify the reach of libraries is being pursued by many libraries, as can be seen in the variety of offerings on the WWW. A noteworthy site is the North Carolina State University library (Morgan, 1994) which, in addition to books, provides links to popular periodicals like Mother Jones (1994). Perhaps the quintessential vision of on-line information access for the "information superhighway" is placing the Library of Congress on the network. The difficulties in converting its current vast holdings of paper books into digital media also illustrates the distance that must be covered. However, the first step in this journey has already been taken as can be seen by the 
Library of Congress's home page (1994). The general vision is simple and powerful: place the holdings of the Library of Congress on-line coupled with flexible search engines, thus providing unprecedented access. Students could pursue virtually any topic, no matter how obscure or popular, without having to worry that the book is not in the inventory of their local library or had already been checked out.

Museums

Museums, like libraries, are great bastions of culture in our society. They too have come on to the WWW providing provocative and useful resources for students. For example, the Exploratorium Science Museum in San Francisco (1994) provides "virtual-exhibits" designed to aid in the understanding of scientific principles and concepts. A Museum of Paleontology has been erected on the WWW by University of California at Berkeley. A diverse collection of dinosaur images and information provides a particularly welcome resource for $\mathrm{K}-12$ students who are often fascinated by our gigantic ancient predecessors. Through these new venues, museums and libraries are continuing their primary task of providing access to cultural artifacts and descriptions of nature. However, the possibilities of access at a distance to so much of their collections introduces order of magnitude differences in the level of access that can be achieved. Of course, these possibilities come at the cost of redefining what is being delivered. Providing a picture of a dinosaur is much different than standing before a fifty-five foot high reconstructed skeleton: The agreed upon "stand-in" for nature has been transformed.

\section{Government Information}

Government information provides a treasure trove for those hoping to understand our society and to those seeking to play watchdog. For example, through accessing government information and statistics, students can re-evaluate newspaper editorials and study the human impact on the environment. Towards this later end, the Environmental Protection Agency (1994) provides numerous data sets and statistics. Similarly, the United States Geological Survey (1994) provides information and curriculum units 
Another example, is the United States Bureau of the Census (1994) which publishes data and analyses through the WWW. Through analysis of these governmental data sets students can examine anthropogenic changes in our environment and evaluate what populations will be affected, including both the number of people and their demographic characteristics. The goal if for students to acquire a deeper sense of their own local area by summarizing its characteristics and contrasting them with other areas. Another valuable resource for such activities comes from an enormous collection of declassified military spy photographs collected over the past 25 years (United States Geological Survey, 1995a) in the hopes that students and researchers can use them to detect changes in our local and global environments; however, currently only a few demonstration images are available over the WWW. The legislative branch of government is publishing the full-text of legislation and the congressional record through the (United States Congress, 1995).

\section{Curriculum and Activities}

The examples above were intended to illustrate the utility of these data sets and also to suggest the tenor of potential projects: Students can go beyond merely reporting facts and figures to using them in service of testing or promoting a theory. Often students need guidance to effectively use the information that can be found in remotely accessible libraries, museums, and government data bases. A traditional way to package such guidance is through prespecified activities or a curriculum. Thus, the WWW provides a new medium to deliver these curriculums. An exacting procedural example is provided through a lab experiment to dissect a frog, turned into a WWW interactive session by the Instructional Technology Program at the Curry School of Education, University of Virginia (Kinzie, 1994). Ample use has been made of images that illustrate the steps involved in the procedure. In addition, snippets of video are provided that show students going through these steps, thus providing a model to imitate. This multi-media presentation permits specification of the laboratory procedures well beyond what can be provided in a textbook. Further, the text, images, and video are flexibly intertwined, thus providing a more integrated context than a videodisk. An even more ambitious effort is demonstrated by 
the Education for Gifted Youth Program (1994) from Stanford University which attempts to provide entire courses in mathematics for gifted high school students. In contrast to coordinated presentations like these, other WWW servers provide lists of curriculum that are available. For example, the Explorer Project (Unified Network Informatics Technology for Education at the University of Kansas, 1994) provides extensive listings of educational material in the areas of math and science some of which can be obtained directly over the WWW. The utility of superb images is exemplified by the University of Illinois Atmospheric Science department who have assembled pictures of various types of clouds (Atmospheric Sciences at University of Illinois at Urbana-Champaign, 1994). This Cloud Catalog consists of unique photographs (slides) of different cloud types, ranging from Cirrus Fall Streaks to the Funnel Cloud. These pictures have been scanned in and are accompanied by descriptive information identifying the cloud type.

Indices

Simple textual searches are not sufficient to index information. Often more useful are indices to information sources that have been created. Many of these indices are organized by subject matter, author, or other standard criteria. Automatic creation of indices exist both by the WAIS searches of selected data bases and by "robots" or "spiders" (e.g., Eichmann, McGregor, and Danley, 1994) that crawl through the WWW and compose traces of its paths and by-ways. In particular, the Lycos search engine from Carnegie-Mellon University (1994) provides a superb facility and was used extensively in the preparation of this paper. However, pattern matching on text is not sufficient. Richer and more flexible indexing strategies are needed. In fact what have emerged are trailblazers (as proposed by Vannever Bush, 1945) who map out whole networks of associations that are worth following -- in fact, this section itself could be viewed as an attempt to trailblaze. In addition, pragmatic indices can be created that are designed to help accomplish tasks (as opposed to subject indices that group together material on a similar topic). Alternatively, students' exploration of the WWW may be best facilitated if they were able to flexibly and explicitly list their goals when accessing a link, thus providing the opportunity to 
maintain an external memory and executive assistant. In any case, the pragmatic structure of the information and resources being provided by the WWW must be more clearly conveyed so that students can mine its extraordinary riches.

\section{Access to Analysis Tools and Raw Data}

A more sophisticated level of access for students to communities of practice provides them the ability to generate custom representations and obtain access to the underlying data, thus permitting novel analyses and interpretations. Often, the form of the data is dictated by the representations employed. These representations are often very complex in that they are highly encoded and are layered on top of other representational systems (Latour, 1988). Not yet present in any of these systems is an attempt to provide scaffolding for novices through the provision of rich contextual information that would deconstruct the representations and provide examples of how these images, data, and tools have been successfully used in practice. This is unfortunately similar to how scientific laws have been presented in didactic classrooms -- formulas presented absent the situations in which they provide explanatory power, thus posing a puzzle to the student why they are valued (Toulmin, 1953). Nonetheless, the appearance of these dynamic tools is an important step in moving education beyond a model of student as consumer to a model of student as active inquirer. The examples presented here are grouped by domain as follows:

\section{Weather maps}

2. Scientific visualizations of climate

\section{Interactive Mapping}

\section{Weather Maps}

Purdue University's Department of Earth and Atmospheric Sciences (1995) has developed a server that allows students to select weather images and data that is updated hourly, thus allowing students to do weather prediction and investigation. 
Scientific Visualization

The tools used by an expert community often serve to help define the basic questions and assumptions used. In particular, scientists in recent years are employing scientific visualizations(3) (SciVs) as a primary means to communicate discoveries and to perform speculative investigations. The extent to which they have permeated scientific practice is demonstrated by picking up any recent issue of Science or Nature and counting how many SciVs can be found. A common use of these visualizations on the WWW is to provide the ability to browse data sets in order to refine one's choice of which data to request. For example, the Lamont-Doherty Earth Observatory of Columbia University (1995) will dynamically render climate data sets as directed through a vast array of parameters as well as provide the underlying data to the user. Similarly, the Pacific Marine Environmental Laboratory of the National Ocean and Atmospheric Administration (1995) renders several oceanic data sets and will deliver the data in spreadsheet form. Another example comes from the Learning Through Collaborative Visualization (CoVis) Project at Northwestern University (1993). Practicing atmospheric scientists were interviewed and their methods and data analyzed, leading to the design of specialized educational software where the students could peruse and construct SciVs of climate and the earth's radiation budget (Learning Through Collaborative Visualization Project, 1995a). These visualizations are provided at multiple levels of detail so as to aid students in detecting large and small grain patterns within the global climate system. Individual points can be queried for their value; by choosing different levels of resolution these data points can refer to relatively small areas (e.g., 2.5 degrees square) or to large areas (e.g., a single scalar for the whole earth).

Interactive Mapping

Evaluating the data that can be obtained over the WWW often requires flexible tools that allow the iterative selection of data and analytical operations on it. Tools like this are becoming increasingly common on the WWW through the use of forms. An example of a WWW server providing 
interactive analysis of data (even before the introduction of forms) is provided by Xerox's map server (1994). This server facilitates the interactive exploration of digital maps through the operations of selecting a part of the globe, zooming in on the globe, and specifying what aspects to portray (e.g. rivers or political boundaries). In this manner, not only is information provided, but an environment for querying and investigating that information is specified. A fascinating example has emerged of an application that combines the information on recent earthquakes with the Xerox map server to provide customized maps of where recent earthquakes have occurred. Hence, by providing applications on a common global platform new applications can be built by linking others together. This philosophy of linking pieces to create larger wholes is fundamental to the methodology of computer science and has been a primary goal of many operating systems (e.g., Ritchie \& Thompson, 1974) -- the WWW now provides such a global operating system for interactive applications. Of course, the emergence of standards for inter-operability should substantially enhance the ease with which such applications can be created.

6. Forging Learning Communities through Communication Mediums on the WWW

This section focuses on how the WWW is being used to forge learning communities between students, teachers, schools, and professionals. The emphasis is on those using the WWW as an interactive(4) communication medium and on sites whose primary goal is to establish learning communities. Interactive mechanisms are still relatively undeveloped on the WWW, but include forums which are similar to newsgroups (messages can be posted and read asynchronous) and chat sessions which emphasize synchronous communication through entering short messages. These facilities have possibilities not shared by their progenitors, namely Usenet newsgroups and Internet Relay Chat (IRC). These possibilities arise from the flexibility of the WWW to incorporate multimedia, hypertextual links, and structured forms. Some of these advantages are realized in the communication mediums reviewed below, in particular, that allow students and teachers to create logs of their activity and in their collaborative construction of web pages. However, we expect development of interactive structured communication like these to be one of the most important developments for 
the establishment of learning communities. The examples provided here are grouped into the following categories:

1. Connecting teachers and students with one another

2. Connecting parents and local communities with schools

3. Connecting students to scientists and other practitioners

Connecting teachers and students with one another This category is broad in that it refers to connections both within a single classroom and across classrooms. The Gonzaga College High School in Washington DC (1995) Earth System Science Community Curriculum is using their web server as the basis for students to file progress reports where they record their activities, list problems or questions, and enumerate the resources they employed that day. Teachers similarly file reports. These reports are available to the entire community, indeed to the entire WWW, though selected portions (e.g., the teachers' reports) are password protected. These communication facilities are integrated into a comprehensive set of services that provide relevant scientific instruction and data, bibliographies, and relevant papers for students to use in accomplishing their project. These facilities provide an excellent example of how the WWW can be used to forge a school-based learning community that is also open to work-based learning communities in that scientists and others could potentially serve as mentors by observing the students on-going work and through understanding the suite of tools and data that help comprise the environment in which they are working.

The CoVis Project has established WWW pages that students and teachers collaboratively construct by adding WWW sites along with a description and annotation (e.g., Learning through Collaborative Visualization, 1995b). These pages serve as a place to share key "finds" on the WWW with each other. Another example of annotating the web is the provision for newsgroup style threads that optionally include pointers to WWW pages (Learning through Collaborative Visualization, 1995c).

Another exemplary project is Web66 (1995a) which helps teachers and schools to start publishing on the Internet by setting up ftp, gopher, and WWW 
servers. While this style of communication does not fit with the interactive motif of this section, Web66 does provide for interactive communication by maintaining a listserv that connects educators supporting WWW servers. Another excellent service provided by Web66 is a comprehensive list of K-12 WWW sites (Web66, 1995b).

The Global Schoolhouse Project is also seeking to build a community between schools. Their WWW server (Craighead, 1994) provides an asynchronous electronic spine as a repository of diverse information including: a description of the project's goals, a list of its participants organized by school with home pages for teachers and students, a "hot" list of software being used by the project (i.e., clicking on the name of a piece of software transfers it via ftp) access to mailing lists and curriculum.

Another area where efforts have been begun but are not yet well developed is in establishing a learning community amongst teachers. This is particularly important since teachers are often shut-off from professional contact with their fellow teachers and researchers due to the physical architecture of educational environments, namely, separate classrooms with one teacher and many students. CCT can provide vital links between teachers, thus allowing them to share professional advice and to adopt new practices and methods. Mechanisms of fostering such change are crucial if new technologies are going to be successfully incorporated into classrooms without having to wait for an new generation of teachers to enter the profession. An example effort in this regard is the Texas Education Network (Tenet) project which is seeking to forge community and expertise amongst the state's educators. One aspect of this is their WWW server (Texas Education Network, 1994) where a wide range of information can be found, including legal, technical, and practical aspects of telecommunications.

Connecting parents and local communities with schools One advantage parents can provide students and teachers is that of an interested audience. The primary audience for students are teachers, thus providing an audience who is vastly outnumbered by the performers. When a school uses the WWW to make student work available to the broad-based audience of the Internet, students suddenly have a new, and greatly expanded audience for their work. 
A number of schools have started to make student work available in this way. Two notable examples are Grand River Elementary School (1994) in Lansing, Michigan, and Hillside Elementary School (1994) in Cottage Grove, Minnesota. Both of these schools assist students in creating their own personal WWW pages, in effect giving the students a personalized presence on the Internet. In an analogous attempt to allow parents access to school life many schools, especially in urban areas, have begun using "voice mail" systems. These systems allow parents to phone the school, and through a series of touch-tone commands, learn about their child's attendance record or daily assignments. These systems have been very successful in alerting parents to the work their students should be doing, and aids parents in monitoring homework and academic progress. If a school is able to make student work available on-line, a leap is made from showing parents what students should be doing to what students are doing. Beyond seeing their own child's work, parents would be able to view the work of other students. This allows parents to see how their child compares to others, so that they can make a self-determination of academic progress that is based upon quality of output, not on grades or class rankings. Furthermore, through the addition of a forms-based interface, parents could provide feedback or critique on their child's work, adding another dimension to its evaluation.

Local communities serve as another primary audience and source of resources for schools. The WWW can serve schools as an alternative mechanism to communicate with their local communities. For example, people who are live in Arlington, Virginia (1994), can get current information about their local public schools on-line. The Houston Independent School District has taken advantage of the excellent Armadillo WWW server at Rice University to announce the mission statement for a new lab school (Perkins \& Castellanos, 1994). The Cottage Grove Elementary School makes community statistics and information about its PTA (Hillside, 1994) available on the same WWW server its students use to produce their personal home pages.

Putting students in touch with experts Few if any WWW sites have facilities to directly put students in contact with practitioners, experts, or scientists. Instead the WWW is helping to publicize mechanisms outside the WWW by which such contact can be arranged. For example, the United States 
Geological Survey (1995b) advertises its "Ask-A-Geologist" service.

7. Collaboration between Students and Work-Based Learning Communities

Again, the WWW is not being directly used to accomplish collaboration between students and practitioners or experts. Instead, some WWW servers are helping to publicize efforts that are occurring using other communication facilities. On of the most fascinating of these is the JASON project which seeks to build community by having students remotely participate in scientific field trips or "telepresence." Such trips are accomplished through highly advanced robots that are capable of exploring the depths of oceanic vents or the inner molten reaches of volcanoes. Students participate by suggesting courses of action and asking questions. Jason's WWW server (Feldman, 1994) aids in this process by providing a basis for teacher in-service education, dissemination of curriculum, and multimedia recapitulations of past explorations.

A possible future use of the WWW to foster communication and collaboration between students and practitioners is to provide a mentor data base. Students would list the type of help they are requesting, while practitioners would list their areas of experience. Further, logistical constraints could be incorporated, such as, available time, preferred modes of communication, and so on. This data base could then be used to do matchmaking between students and practitioners.

\section{Adopting students work into a community of practice}

In this area as well, the WWW does not yet have many facilities for students to build or engage in collaborations with practitioners. Hence, we again concentrate on WWW servers that describe such activities conducted through alternative mediums. In particular, the Global Lab Project at the Technical Education Resource Center (TERC) is linking classrooms around the globe with each other and with experts in order to accumulate student data for scientific use. One project had students around the United States collect experimental data on acid rain and then pool the data for analysis by experts in the area. This effort produced a unique and valuable resource 
for environmental scientists. Recent efforts are seeking to have students collect data on levels of ozone and other quantities crucial to observing patterns of global environmental change. The international flavor of the project is conveyed by their WWW server (TERC, 1994) which contains movie clips from Global Lab classes in Nigeria, the Czech Republic, Mexico, and Washington, D.C. A strength of TERC's projects is that they have found ways for students' work to be of genuine use and of interest to scientists, thus providing the basis for a relationship based on mutual benefit. This is consonant with the philosophy of their chief scientist, Robert Tinker (1994), who seeks to transform students and schools from isolated islands of concept learning into powerful social resources. In a similar vein, Vice-President Gore (1993) is leading Project Globe which has called for scientists for organize and lead student data collection into environmental conditions, such as, air and water pollution, stratospheric ozone levels, and carbon-dioxide emissions.

In summary, WWW servers provide valuable aid towards the goal of enabling schools to forge learning communities. WWW servers serve as central repositories of general project information, software, expert tools, home page biographies, and mailing lists. In this way, the WWW servers provide a common infrastructure which all can access equally(5). This provides a place to accumulate results from more transient communication mediums like video conferences and email. WWW sites are evolving as a medium for newly formed communities to consolidate identities, build shared vocabularies and expertise. As the WWW evolves to support interactive communication more fully it should prove better matched to the goals of creating learning communities.

\section{The Need for WWW Educational Server Development Guidelines}

To date most resources on the WWW have been developed without the specific goal of fostering K-12 learning communities. Yet, as the above examples show, even without this aim WWW resources have been developed that are of extraordinary value to schools and learning communities. In order to continue to advance in this process of facilitating the construction of learning communities through the WWW an explicit characterization of how to 
accomplish this goal is needed. The beginning point in this process is a recognition that Educational WWW Servers (EWS) are needed that embodies a distinctive architecture. In particular, an EWS must embody the following features:

1. EWSs' need to provide "just-in-time" curriculum for students. This style of curriculum differs from the standard prearranged sequences of material found in most textbooks and is organized so that students get access to resources they need in order to solve their current on-going problem. This style of problem-solving is no different than that employed by adults in the completion of their tasks. When an adult needs to build a bookshelf they usually do not engage in a four month sequence on wood working, but look up bookshelves in the index of a "how-to" book. Similarly, students will access curriculum resources in order to achieve their short and long-term goals. Necessary components of such curriculum are:

Information resources such as those surveyed in section 4 above. Activity structures must be provided that aid students to learn the conceptual structures of a domain (e.g., There is overarching category that unites visible light with imperceptible radiation of longer and shorter wavelengths, that is, the electro-magnetic spectrum) and to build important artifacts for the investigation of physical phenomena (e.g., a pyrometer that can detect infrared radiation). These activity structures should identify materials required as well as place the activities into a social structure (e.g., performed as a small group or whole class). This is in contrast to the assumed model of use on WWW servers today, namely, an single individual accessing information.

Assessment procedures designed to aid students and teachers in understanding a student's level of competency in order to direct them student to the resources and activities described above. These assessments can also be keyed to educational standards such as Goals 2000 or district-based mandates. In short, an EWS must have more than content, it must also have that content placed into larger contexts of use. In addition, assessment procedures can help students monitor their own progress, thus promoting 
their executive and meta-cognitive abilities to lead their own learning.

Matching resources to teaching and learning tasks is the primary design objective of a EWS and can provide rich opportunities for important new design work in computer science, networking, and learning sciences, particularly around issues of information access, intelligent agents, teacher development, domain cross-referencing, and cognitive development in the subject areas. Some preliminary ideas in this direction are enumerated in the section below on a geosciences EWS. In addition, work-based learning communities can aim to provide versions of their tools and data sets that are surrounded by a rich contextual background to help ease the difficulty of learning their use. This would involve, for example, making the units of the data explicit and their meaning explained in everyday terms (e.g., a joule is the amount of energy spent in lifting a lemon one meter, Emiliani, 1992).

2. The EWS should offers facilities for authoring and browsing user commentaries. These commentaries provide a living dimension to the EWS, so that it is continually open to the design work that its users are doing in seeking to utilize its resources in their local situations and for their specific purposes. Commentaries can discuss the usefulness of specific resources and the activity structures designed to provide context for their use, and suggest modifications that "make them work better." This design goal of developing a self-improving or cybernetic EWS can provide a major advantage over any previous static educational innovation in curriculum. We would argue that it provides more of a free market for teaching and learning resources which is evolutionary in its nature (survival through use in selection) rather than top-down from instructional designers -- which is often too elite and ill-suited to the vicissitudes of local situation appropriacy in educational settings. In addition, these authoring facilities provide a means for teachers and students to originate their own curricular ideas and to engage in collaborative knowledge construction and debate. The investigation of how to structure hypermedia documents to facilitate learning communities has 
been an active area of investigation (O'Neill, Gomez, \& Edelson, 1994) that can be utilized here in designing mechanisms to foster both divergent and convergent lines of thought.

3. The EWS also offers a facility for teachers and students to contact others on the network who share a particular interest with them. These contacts can be as simple as WWW entries containing email addresses or they can grow to be as complex as WWW-based protocols that assist teachers and students in making contact with people that have appropriate expertise at the time it is needed in a learning situation. The WWW is now poorly developed in its interactive communicative functionality. In particular, little has been done as regards either infrastructure or content to set up opportunities for work-based learning communities. Explicit attention must be paid to this issue. A primary critique of current educational practice is that it does not "transfer" to the work-place. As critiques of the notion of transfer have pointed out, connections between subject matter that transfer are not inherent, rather they are constructed via analogies and social agreement (Pea, 1987). The work and educational community must join together to forge connections between their, too often disparate, learning communities. Opportunities can be found for students to investigate issues and potentialities that the work-based communities do not have the time or energy to pursue. Building on Simon's (1969) insight that economic decisions are limited by bounded rationality we can easily recognize that any decision we make is made heuristically within an ecological domain where all relevant resources are limited. Our schools provide a huge resource for performing additional research on these decisions. An obvious example is the researching of alternative energy sources, such as, solar power. As technologies rapidly evolve the economies of scale for energy production change -- students can provide an ever ready pair of eyes inspecting such possibilities for fiscal viability. In addition, professionals work in established paradigms and modes of thought. These paradigms guide productive work, yet they can also blind one to productive alternatives. Again the eyes of our students can provide sponsor the fruitful production of new hypotheses that incorporate 
more divergent influences or randomness than a fuller member of a learning community. This random variation is the prerequisite for the evolutionary selection of ideas to occur. The professional community can easily critique and prune such ideas; the role of our students can be to generate and design new possibilities. Through these designs and the subsequent critiques profound learning can occur. Imagine how much more valuable it would be for each class of our students to have proposed alternative energy sources, rather than for each individual student to be successful in passing a math competency exam. In addition to critiquing the work of students, work-based learning communities could be formed that would provide for mentoring of students, provide opportunities for joint work, and mechanisms to acknowledge when the work of students was sufficiently useful that it warranted further investigation or incorporation into the community's corpus.

Overall, it must be emphasized that EWSs will only develop value for education insofar as educators and other educational agents (e.g., parent, peers, and workers) take action to advance teaching and learning design, usability, and promote their broader adoption. This serves to seed a learning web, and establish new distributed communities for educational reform.

4. Educational servers fundamentally need powerful search engines for specifying teaching and learning tasks by educators which then guide intelligent agent-based search throughout WWW servers. The kinds of considerations in designing such searches include query by progressive refinement around subject domain, topic within domain (cross-referenced interdisciplinary curriculum resources probably requiring indexing of some kind), grade level appropriacy (but ultimately learner level irrespective of grade). The key here is turning up resources that are "good enough," so that educators and users find that the time and effort costs of browsing and search are worth it, relative to the benefits derived for teaching and learning.

10. The Geosciences Server: a sample Educational WWW Server 
EWSs, if they evolve, will take many shapes; below, we offer a characterization of one now being designed, that is, the Geosciences Server being built as part of the CoVis project. The CoVis Geosciences server is being developed by multiple institutions that include Northwestern University, University of Illinois, University of Michigan, University of Colorado, Exploratorium Museum, and select K-12 schools. Materials will include: curriculum, activities, assessment materials, data sets, editorially-reviewed student projects, directory services for participants, and a comprehensive indexing scheme. Part of the design effort is to seek to assure compatibility of server resources, materials, and activities with the leading state frameworks and emerging national science education standards.

The ultimate goal of the server is to develop a model for how communications technologies can aid the establishment of learning communities. One part of the design focuses on the delivery of curriculum so as to be useful to a school-based learning community. This curriculum incorporates the following parts:

1. An accounting of the basic conceptual structures of a field presented as a set of categories and processes. This account is consistent with cognitive science descriptions of how scientific knowledge is organized (Chi, 1992; Gentner, 1989).

2. Activities designed to help students move from their everyday categories to the specialized categories of science. These activities should accomplish this by demonstrating the worth of the categories. That is, the categories should be argued for on the basis of their worth and not on the basis of authority.

3. Systems are provided which utilize the above categories and processes for their analyses. For example, when investigating the earth-sun system and in particular the process by which the earth maintains an energy balance (or radiative equilibrium) important categories are incoming light (or insolation), amount of reflectivity and absorption, and resulting temperature. Hence, the student would be asked to investigate the system by alternately doing laboratory experiments to 
experience the categories processes of light and energy and so on and then showing how they play out in the earth-sun system currently under study. In doing this the student is encouraged to build on their everyday experience of climate (i.e., their everyday knowledge of the earth-sun system) to understand the category of radiation and its processes. Similarly, students are encouraged to use experience gathered in laboratory experiments of light, radiation, and temperature to understand the Earth-sun system. Hence, the focus becomes forging relations from categories and processes to systems.

4. These two way relations are explicitly represented at some level of detail to aid students in making these connections. For example, relations might be provided for an analogous situation, say the energy budget of the human body, which too must balance its incoming energy (consumed in food not light energy) with its outgoing energy.

5. Diagnostic instruments are provided to help teachers identify what categories and processes students hold so as to help recommend activities for students to perform to persuade them of the utility of scientific concepts. For example, students who do not believe in the existence of infrared light could be shown it visibly though charge coupled devices (CCD) calibrated to detect such light. Such a demonstration would show differential brightness over the surface of a human's body showing which areas were warmer and cooler. This acquaintance with a new category of infrared light could then be parlayed into the system of the earth-sun by examining visualizations of the infrared radiation emitted by the earth and relating it to the infrared radiation emitted by people.

There are several other areas to be developed that are not discussed for reasons of space. These include a mentor data base, richly contextualized data sets, and tools for data analysis specialized for student use.

\section{Conclusion}

The WWW is in its infancy. As it grows and matures many different communities will customize it and shape it to meet their specific needs. The K-12 teaching and learning community will be no exception. We have 
attempted to point out here that the needs of this community are diverse and that already the K-12 community has found resources on the WWW that are valuable. The demands of education are especially rigorous, particularly when we consider the development of both school-based and work-based learning communities. We have argued that there is a long way to go before the WWW can serve as a major tool for building educational communities. Specifically, the support for interactive communications is woefully underdeveloped, but is receiving significant attention and growth. We have provided a progressive list detailing increasing depth in the formation of learning communities -- we urge architectural innovations for WWW interactive communications be evaluated with respect to this list. Hopefully, these suggestions will be used to spur thinking and development around customizing the WWW and its applications to meet needs of schools and education more broadly wherever it occurs.

\section{Bibliography}

Arlington, Virginia (1994). Arlington county schools. [Online] Available at http://www.co.arlington.va.us/school.htm.

Bush, V. (1945). As we may think. The Atlantic Monthly, Vol. 176, 101-108.

Chi, M.T.H. (1992). Conceptual change within and across ontological categories: Examples from learning and discovery in science. In R. Giere (Ed.) Cognitive models of science: Minnesota studies in the philosophy of science.

Carnegie-Mellon University (1994). The lycos home page: Hunting WWW infomation. [Online] Available at http://lycos.cs.cmu.edu/. For more information contact Michael L. Mauldin at email address fuzzy@cmu.edu" fuzzy@cmu.edu.

Craighead, L.M. (1994). Global schoolhouse project: Linking kids around the world. [Online] Available at http://k12.cnidr.org/gshwelcome.html. For more information the author 
can be contacted at (919) 248-9226, street address is Laura M.

Craighead, CNIDR, MCNC Information Technologies Division, 3021

Cornwallis Road, Research Triangle Park, NC 27709; for more

information send email tolmc@cnidr.org.

Department of Atmospheric Sciences at University of Illinois at Urbana-Champaign (1994). Cloud Catalog. [Online] Available at http://www.atmos.uiuc.edu/covis/modules/clouds/html/cloud.home.html. Address questions to Dr. Mohan Ramamurthy at email address mohan@uiatma.atmos.uiuc.edu.

Dewey, J. (1938). Experience and education. New York: Collier Books.

Eckert, P. (1989). Jocks and burnouts : Social categories and identity in the high school. New York: Teachers College Press.

Education Program for Gifted Youth (1994). Education program for gifted youth. [Online] Available at http://kanpai.stanford.edu/epgy/pamph/pamph.html. Street address is Education Program for Gifted Youth, Ventura Hall (MC 4115), Stanford University, Stanford, CA 94305-4115. For more information send email to ravaglia@epgy.stanford.edu.

Eichmann, D., T. McGregor and D. Danley (1994). The RBSE spider Balancing effective search against web load, First International Conference on the World Wide Web, Geneva, Switzerland, May 25-27, 1994. Also in Computer Networks and ISDN Systems, v. 4, n. 2, 1994, pp. 281-288.

Emiliani, C. (1992). Planet earth: Cosmology, geology, and the evolution of life and environment. New York: Cambridge University Press.

Environmental Protection Agency (1994). U.S. environmental protection agency WWW server. [Online] Available at http://www.epa.gov/. Questions can be sent to email address 
internet_support@unixmail.rtpnc.epa.gov.

Exploratorium Museum (1994). Digital library exploratorium exhibits. [Online] Available at http://www.exploratorium.edu/imagery/exhibits.html. For more information contact at The Exploratorium, 3601 Lyon Street, San Francisco CA 94123 tel: (415) 563-7337.

Feldman, G.C. (1994). The jason project. [Online] Available at http://seawifs.gsfc.nasa.gov/JASON/JASON_HOME.html. For more information send email to gene@seawifs.gsfc.nasa.gov, phone number (301) 286-9428.

Gentner, D. (1989). The mechanisms of analogical learning. In Vosniadou, S. \& Ortony, A. (Eds.). Similarity and logical reasoning. (pp. 199-240). New York:Cambrdige University Press.

Gonzaga College High School (1995). Earth system science community curriculum overview. [Online] Available at http://www.circles.org/ESSCC/overview/overview.html.

Gore, A. (1993). Earth in the balance. pp 354-360. New York: Plume.

Grand River Elementary School (1994). Brad marshall's 5th Grade class (1994). [Online] Available at http://ah3.cal.msu.edu/GR/grintro.html.

Gray, M.K. (1994). Measuring the size and growth of the web. [Online] Available at http://web.mit.edu/afs/sipb/user/mkgray/ht/web-growth.html. The author's home page is at http://www.mit.edu:8001/people/mkgray/mkgray.html .

Hill, P.J. (1982). Communities of learners: Curriculum as the infrastructure of academic communities. In J. Hall \& B. Kevles (Eds.) In opposition to the core curriculum: Alternative models for undergraduate education. Westport, CO: Greenwood Press. 
Hillside Elementary School (1994). Hillside elementary home page. [Online] Available at http://hillside.coled.umn.edu/. For more information send email to events@hillside.coled.umn.edu.

Kinzie, M. (1994). The interactive frog dissection: An on-line tutorial. [Online] Available at http://curry.edschool.virginia.edu/ insttech/frog/.

Kuhn, T.S. (1962). The structure of scientific revolutions. Chicago: Chicago University Press.

Lamont-Doherty Earth Observatory of Columbia University (1995). LEDO climate group home page. [Online] Available at http://rainbow.ldeo.columbia.edu/datacatalog.html. For more information send email to benno@ldeo.columbia.edu.

Latour B. (1988). Drawing things together. In M. Lynch \& S. Woolgar (Eds.). Representation in scientific practice. Cambridge, MA: MIT Press.

Lave, J., \& Wenger, E. (1991). Situated learning: Legitimate peripheral participation. Cambridge: Cambridge University Press.

Learning Through Collaborative Visualization Project (1993). Learning Through Collaborative Visualization. [Online] Available at http://www.covis.nwu.edu/. For more information send email to bfishman@covis.nwu.edu.

Learning Through Collaborative Visualization Project (1995a). Greenhouse Effects Visualizer. [Online] Available at http://www.covis.nwu.edu/gev.html. For more information send email to gordin@covis.nwu.edu.

Learning Through Collaborative Visualization Project (1995b). Pointers to global warming resources [Online] Available at 
http://www.covis.nwu.edu/storage/GlobalWarming.html. For more information send email to gordin@covis.nwu.edu.

Learning Through Collaborative Visualization Project (1995c). Threads of conversation. [Online] Available at http://www.covis.nwu.edu/storage/threads.html. For more information send email to gordin@covis.nwu.edu .

Library of Congress (1994). Library of congress home page. [Online] Available at http://lcweb.loc.gov/homepage/lchp.html. For more information send email to lcweb@loc.gov .

Morgan, E.L. (1994). The NCSU libraries webbed information system. [Online] Available at http://dewey.lib.ncsu.edu/. The author's home page is http://www.lib.ncsu.edu/staff/morgan/morgan.html .

Mother Jones (1994). Mother jones magazine. [Online] Available at http://www.mojones.com/mojo_magazine.html. Street address at MOTHER JONES, 731 Market Street, Suite 600, San Francisco, CA 94103. For more information send email to backtalk@mojones.com.

O'Neill, D.K., Gomez, L.M. and Edelson, D.C. (1994). Collaborative Hypermedia for the Classroom and Beyond: A Year's Experiences with the Collaboratory Notebook. In Haake, J.M. (ed.), Proceedings of the CSCW '94 Workshop on Collaborative Hypermedia Systems, Oct. 22, 1994, Chapel Hill, North Carolina.

Pacific Marine Environmental Laboratory of the National Ocean and Atmospheric Administration (1995). PMEL home page. [Online] Available at http://ferret.wrc.noaa.gov/ferret/main-menu.html.

Pea, R. D. (1987). Socializing the knowledge transfer problem. International Journal of Educational Research, 11, 639-663.

Perkins, D. \& Castellanos, J. (1994). The Rice School/La Escuela Rice: A new way of learning in HISD. [Online] Available at 
http://riceinfo.rice.edu/armadillo/Rice/dev.html. Contact the authors directly through email at dperkins@tenet.edu and joel@es.rice.edu, respectively.

Purdue University's Department of Earth and Atmospheric Sciences (1995). Purdue weather processor. [Online] Available at http://thunder.atms.purdue.edu/. Send questions to Daniel Vietor at email address devo@cell.atms.purdue.edu.

Ritchie, D.M.\& Thompson, K.L. (July, 1974). The UNIX time-sharing system. Communications of the ACM.

Schank, R. \& Cleary, C. (1994). Engines for Education. [Online] Available at http://www.ils.nwu.edu/ e for_e/.

Simon, H.A. (1969). The sciences of the artificial. Cambridge, MA: MIT Press.

TERC (1994). TERC home page. [Online] Available at http://hub.terc.edu/terc.html. For more information send email to communications@hub.terc.edu.

Texas Education Network (1994). The texas education network (TENET). [Online] Available at http://www.tenet.edu/tenet-info/main.html. For more information send email to web-master@tenet.edu.

Tinker, R. (1994). Mapware: Educational Applications of Geographic Information Systems. [Online] Available at http://hub.terc.edu:70/0/hub/owner/TERC/Chief_Scientist/Mapware.txt. Author can be reached at the street address, The Technical Education Research Centers, 2067 Massachusetts Ave., Cambridge, MA 02140, and at the phone number (617) 547-0430.

Toulmin, S. (1953). The philosophy of science. New York: Harper \& Row.

Toulmin, S. (1972). Human understanding: The collective use and 
evolution of concepts. Princeton, NJ: Princeton University Press.

Unified Network Informatics Technology for Education at the University of Kansas (1994). Explorer. [Online] Available at http://unite.tisl.ukans.edu/xmintro.html $>$.Send comments and questions to email address explorer@unite.tisl.ukans.edu.

United States Bureau of the Census (1994). U.S. bureau of the census home page. [Online] Available at http://www.census.gov/. For more information send email to address gatekeeper@census.gov.

United States Congress (1995). Thomas: Legistlative information on the internet. [Online] Available at http://thomas.loc.gov/. For more information send email to thomas@loc.gov.

United States Geological Survey (1994). United states geological survey home page. [Online] Available at http://info.er.usgs.gov/education/index.html. Street address is U.S. Geological Survey, MS915 National Center, Reston, VA 22092, USA. For more information send email to webmaster@www.usgs.gov.

United States Geological Survey (1995a). Declassified Intelligence Satellite Photographs. [Online] Available at http://edcwww.cr.usgs.gov/dclass/dclass.html. Street address is U.S. Geological Survey, MS915 National Center, Reston, VA 22092, USA. For more information send email to webmaster@www.usgs.gov.

United States Geological Survey (1995b). Ask-a-Geologist [Online] Available at http://walrus.wr.usgs.gov/docs/ask-a-ge.html. Street address is U.S. Geological Survey, MS915 National Center, Reston, VA 22092, USA. For more information send email to webmaster@www.usgs.gov.

Vygotsky, L. S. (1978). Mind in society: The development of the higher psychological processes. Cambridge, MA: Harvard University Press (Originally published, 1930). 
Web66 (1995a). A K 12 World Wide Web Project. [Online] Available at http://web66.coled.umn.edu/. For more information send email to WebMaster@web66.coled.umn.edu.

Web66 (1995b). WWW Schools Registry. [Online] Available at http://web66.coled.umn.edu/schools.html. For more information send email toWebMaster@web66.coled.umn.edu.

Wittgenstein, L. (1967). (Originally published in 1949).Philosophical Investigations. Oxford: Blackwell.

Xerox Palo Alto Research Center (1994). Interactive map server. [Online] Available at http://pubweb.parc.xerox.com/map/.

Zakon, R.H. (1994). Hobbes' internet timeline v1.1. [Online] Available via email to timeline@hobbes.mitre.org. Automatic reply includes timeline. For questions, send email to author at hobbes@hobbes.mitre.org.

Footnotes

1 Of course, it can be said that all communities are "learning communities." Hence, implicit in distinctively labeling some communities as learning commuities is a normative notion of what knowledge these communities should aspire towards. For example, in an ethnography of high school life (Eckert, 1989) found students primarily learning from one another, but almost none of this learning went beyond learning the social customs of high school culture. In contrast, within a learning community students engage in acquiring conceptual structures and explanatory systems useful to understand and transform their physical, social, and psychological world.

2 This term refers to increasing integration of computational processes with communication mediums. The primary characteristic of a computational communication medium is the ability to not only transmit and receive information, but also to specify the execution of complex procedures. Such 
integration has become commonplace not only in the Internet, but also in telephone systems through the introduction of automated interaction systems. In contrast, term "computer-mediated communications" is much broader, encompassing not only CCTs but also any communication modality that utilizes computers whether or it allows the embedding of complex procedures (e.g., e-mail or newsgroups).

3 As used here, a scientific visualization refers to an image rendered through high-speed computer graphics that is based on a numerical data set that describes some quantity in the world. For example, temperatures around the world can be rendered as a color image, typically mapping cold temperatures to blue hues and warmer temperatures to yellow and red hues.

4 The WWW can be considered interactive in that pages are retrieved in response to clicking on hypertext pointers. In contrast, we distinguish interactive communications to refer to dialogue, with the paradigmatic example being two people in conversation. Similarly embraced are epistolary exchanges such as found on newsgroups and email. This point is belabored here so as to avoid the conflation between clicking on hypertextual links and dialogue (Schank \& Cleary, 1994). Dialogue, in contrast to clicking on hypertext links, is social and as such opens the possibility for negotiation of meaning and disagreement as well as the deepening of human relationships which form the obvious center of any learning community.

5 This is currently true, of course, only in principle, since access to the Internet is present in only a few schools. Hence, a priority for the education community and for the general body politic must be to ensure equity of access, else the learning communities we seek to build will be closed to segments of the population -- this inequity will injure not only the disenfranchised but will also diminish the quality and range of the learning communities we build by restricting the diversity of thought they possess. 